\title{
Avaliação do padrão estafilococos coagulase positiva estabelecido pela legislação brasileira para massas alimentícias
}

Evaluation of the coagulase-positive staphylococci standard required by Brazilian regulations for pasta

\section{Autores | Authors \\ \Mário Sérgio Azevedo RESTA \\ Serviço Nacional de Aprendizagem Indus- trial (SENAI) \\ Departamento Regional do Paraná (SENAI/ \\ Área de Serviços Tecnológicos e Inovação \\ (STI) \\ Rua Belém, 844 - Centro CEP: 86026-000 \\ Londrina/PR - Brasil e-mail:mario.resta@pr.senai.br \\ Tereza Cristina Rocha Moreia de OLIVEIRA \\ Universidade Estadual de Londrina (UEL) Departamento de Ciência e Tecnologia de Alimentos Londrina/PR - Brasil e-mail: terezaoliveira@yahoo.com.br}

$\triangle$ Autor Correspondente / Corresponding Author

Recebido / Received: 05/07/2013 Aprovado / Approved: 29/11/2013

Publicado / Published: dez./2013

\section{Resumo}

A multiplicacão de Staphylococcus aureus e a produção de enterotoxinas estafilocócicas dependem de fatores intrínsecos e da temperatura de armazenamento dos alimentos. O objetivo deste trabalho foi discutir o padrão estafilococos coagulase positiva (ECP) para massas alimentícias, estabelecido pela RDC n. ${ }^{\circ} 12$ de 2001 da ANVISA, baseando-se nos resultados de atividade de água $\left(\mathrm{a}_{\mathrm{w}}\right)$, potencial hidrogeniônico $(\mathrm{pH})$ e contagem de ECP. Cinquenta amostras de 25 tipos de massas de treze marcas diferentes foram analisadas. A contagem de ECP de todas as amostras foi menor que 10 Unidades Formadoras de Colônia por grama (UFC/g), inferior a 5,0 × $10^{3} \mathrm{UFC} / \mathrm{g}$, estabelecido como limite máximo pela legislação. As médias de $\mathrm{a}_{\mathrm{w}}$ das massas secas com e sem recheio variaram entre 0,70 e 0,61, respectivamente, o que impossibilita a multiplicação de ECP e produção de toxina. Por outro lado, a média de $a_{w}$ das massas frescas foi de 0,96 , o que propicia o desenvolvimento desse padrão microbiológico. Os resultados obtidos neste trabalho indicam que a $a_{w}$ poderia ser utilizada como parâmetro para determinar em quais tipos de massas o padrão ECP deveria ser pesquisado, ou seja, para massas alimentícias cruas que possibilitassem a multiplicação de Staphylococcus spp. $\left(\mathrm{a}_{\mathrm{w}}>0,86\right)$.

Palavras-chave: Regulamentação; Atividade de água; pH; Staphylococcus spp.; Enterotoxina.

\section{Summary}

The growth of Staphylococcus aureus and the production of staphylococcal enterotoxins depend on intrinsic food factors and the food storage temperature. The aim of this study was to discuss the coagulase-positive staphylococcal count limit (CPS) for pasta, established by RDC no 12, 2001, ANVISA, based on the results of water activity $\left(\mathrm{a}_{\mathrm{w}}\right)$, hydrogenionic potential $(\mathrm{pH})$ and the CPS count. Fifty samples of 25 types of pasta from 13 different brands were analyzed. The CPS count of all the samples analyzed was less than 10 Colony-Forming Units per gram $(\mathrm{CFU} / \mathrm{g})$, below the limit of $5.0 \times 10^{3} \mathrm{CFU} / \mathrm{g}$, established by Brazilian Legislation. The average $a_{w}$ for dry pasta with and without stuffing varied between 0.70 and 0.61 , which prevents the development of CPS and toxin production. On the other hand, the average $a_{w}$ for fresh pasta was 0.96 , which allows for the growth of CPS. The results of this study indicate that $\mathrm{a}_{w}$ may be used as a parameter to determine in which kind of pasta the CPS count should be done, ie for pasta that allow for the development of Staphylococcus spp. $\left(a_{w}>0.86\right)$.

Key words: Food regulations; Water activity; pH; Staphylococcus spp.; Enterotoxin. 


\section{Introdução}

Mais de treze milhões de toneladas de massas alimentícias são produzidas anualmente por mais de quarenta e cinco países (IPO, 2011). O Brasil ocupa a terceira posição de maior produtor e consumidor em volume, atrás apenas da Itália e dos Estados Unidos. Em 2011, cerca de 1,3 milhão de toneladas foi produzido internamente, e mais de 8 mil toneladas foram exportadas (ABIMA, 2012). Em 2011, o consumo interno de massas alimentícias no Brasil foi de aproximadamente 1,2 milhões de toneladas, o que colocou o Brasil apenas em vigésimo segundo lugar no consumo mundial per capita desse produto (cerca de 6,2 kg/ano) (IPO, 2011).

A RDC n²63, de 22 de setembro de 2005, da ANVISA (BRASIL, 2005), atualmente em vigor no Brasil, não estabelece o padrão de identidade e qualidade das massas alimentícias, que anteriormente era regulamentado pela Resolução RDC n 93, de 31 de outubro de 2000, da ANVISA (BRASIL, 2000). Essa resolução trazia, entre outras, características sensoriais, físicas, químicas e físico-químicas para esta categoria de produtos (BRASIL, 2000). A RDC n 12, de 2 de janeiro de 2001, da ANVISA, estabelece os padrões microbiológicos para os alimentos em geral, e é a única referência nacional para a avaliação das condições microbiológicas de alimentos no Brasil (BRASIL, 2001). Os padrões microbiológicos para massas alimentícias incluem limites para Bacillus cereus $\left(5 \times 10^{3}\right.$ UFC/g), Coliformes a $45^{\circ} \mathrm{C}\left(10^{2} \mathrm{UFC} / \mathrm{g}\right)$, Salmonella sp. (Ausência em $25 \mathrm{~g}$ ) e Estafilococos Coagulase Positiva $\left(5 \times 10^{3} \mathrm{UFC} / \mathrm{g}\right)($ BRASIL, 2001).

A enumeração de ECP é reconhecida internacionalmente como um padrão microbiológico de segurança de alimentos e importante indicador das condições higiênico-sanitárias da sua produção e conservação. A sua relação com as condições higiênicosanitárias dos alimentos está ligada ao fato de que o principal reservatório natural de Staphylococcus aureus é o ser humano, na pele, mucosas e, principalmente, no trato nasofaríngeo de portadores assintomáticos (TONDO e BARTZ, 2012). Dentre os padrões estabelecidos pela legislação, destaca-se o fato de os limites máximos de Estafilococos Coagulase Positiva (ECP) e de B. cereus serem os mesmos $\left(5 \times 10^{3} \mathrm{UFC} / \mathrm{g}\right)$, uma vez que $B$. cereus é encontrado amplamente na natureza e contamina facilmente cereais e farinhas (KOTIRANTA et al., 2000), ao contrário de Staphylococcus spp., que tem o ser humano e os animais como reservatórios naturais (GENIGEORGIS, 1989). A forma como foram agrupados os produtos também chama a atenção porque todos os tipos de massa foram incluídos em uma mesma categoria, independentemente de suas características distintas (secas, frescas, conservadas sob refrigeração, com ou sem recheio, entre outras).
A intoxicação estafilocócica ocorre devido à ingestão de alimentos contaminados com enterotoxinas termoestáveis produzidas, principalmente, por S. aureus. A produção das enterotoxinas é influenciada por vários fatores intrínsecos do alimento, tais como tamanho do inóculo inicial, competição da microbiota, $\mathrm{pH}$, concentração de cloreto de sódio e atividade de água, assim como pela temperatura de armazenamento (JAY, 2005; GENIGEORGIS, 1989).

Apesar da exigência da legislação e do expressivo desempenho brasileiro no mercado mundial de massas alimentícias, pouco se tem estudado sobre este tipo de produto antes do seu preparo, principalmente no que diz respeito aos seus padrões microbiológicos. O objetivo do presente trabalho foi discutir o padrão ECP estabelecido pela RDC n 12/2001 - ANVISA (BRASIL, 2001) para massas alimentícias com base nos resultados da análise de amostras de marcas variadas, coletadas em diversos pontos de venda. Valores de atividade de água $\left(a_{w}\right)$ e de potencial hidrogeniônico $(\mathrm{pH})$ foram determinados com a finalidade de se obter subsídios para justificar ou contestar o referido padrão microbiológico.

\section{Material e métodos}

\subsection{Amostragem}

O item 10 - farinhas, massas alimentícias, produtos para e de panificação (industrializados e embalados) e similares, descrito na RDC n ${ }^{\circ} 12 / 2001$ da ANVISA (BRASIL, 2001) é dividido em 13 alíneas diferentes, enumeradas de "a" a " $n$ ". As amostras analisadas neste trabalho pertenciam à alínea " $b$ ", a qual inclui massas alimentícias secas, com ou sem ovos, com ou sem recheio; massas frescas, cruas e não fermentadas, com ou sem ovos, com ou sem recheio e cobertura; e similares, refrigeradas.

As 50 amostras de massas alimentícias foram analisadas no mesmo dia em que foram coletadas nos pontos de venda. As coletas ocorreram no período de junho a dezembro de 2012, em 4 pontos de vendas distintos, pertencentes a redes de supermercados existentes na cidade de Londrina, PR. Em cada coleta foram adquiridos diferentes tipos e marcas, procurando-se evitar repetições. Treze marcas diferentes, envolvendo 25 variedades de massas alimentícias entre formatos e especificações, foram analisadas (Tabela 1).

\subsection{Preparo das amostras para cultivo}

Alíquotas de $25 \mathrm{~g}$ de cada amostra de alimento foram pesadas assepticamente e homogeneizadas com $225 \mathrm{~mL}$ de água peptonada 0,1\% (SILVA et al., 2007). Depois de um período de 30 a 60 minutos sob refrigeração, as amostras foram submetidas à homogeneização em 
Tabela 1. Tipos de massas alimentícias e número de amostras analisadas neste trabalho.

\begin{tabular}{|c|c|}
\hline Marcas & Tipos de massas alimentícias \\
\hline A & macarrão seco - ave maria $(n=1)$; alfabeto $(n=1)$ \\
\hline B & macarrão seco - espaguete $(n=1)$; ave maria $(n=1)$ \\
\hline C & macarrão seco - padre nosso $(n=1)$; concha $(n=1)$; letrinhas $(n=1)$; ave maria $(n=1)$ \\
\hline D & capeletti fresco c/ recheio de frango $(n=1)$; ravióli fresco c/ recheio de carne $(n=1)$; macarrão fresco - talharim $(n=1)$ \\
\hline E & $\begin{array}{l}\text { macarrão fresco - talharim }(n=1) \text {; nhoque fresco de batata s/ recheio }(n=6) \text {; ravióli fresco c/ recheio de carne }(n=2) \text {; } \\
\text { capeletti fresco c/ recheio de frango }(n=1) \text {; capeletti fresco } c / \text { recheio } 4 \text { queijos }(n=2) \text {; capeletti fresco } c / \text { recheio de } \\
\text { carne }(n=1) \text {; macarrão fresco - talharim }(n=1) \text {; ravióli fresco } c / \text { recheio de frango }(n=1) \text {; ravióli fresco } c / \text { recheio de } \\
\text { carne }(n=1) \text {; ravióli fresco } c / \text { recheio de queijo }(n=1) \text {; massa fresca p/ pastel }(n=1)\end{array}$ \\
\hline $\mathrm{F}$ & macarrão seco - spirali $(n=1)$ \\
\hline G & macarrão seco - espaguete $(n=1)$; caramujinho $(n=1)$; argolinha $(n=1)$ \\
\hline $\mathrm{H}$ & $\begin{array}{l}\text { macarrão seco - concha }(n=1) \text {; tipo caseiro - talharim c/ ovos }(n=1) \\
\text { capeletti seco c/ recheio de ricota e espinafre }(n=2) ; c / \text { recheio de carne }(n=4) ; c / \text { recheio de queijo }(n=2)\end{array}$ \\
\hline I & massa fresca $p /$ pastel $(n=1)$ \\
\hline J & massa fresca $p /$ pastel $(n=2)$ \\
\hline K & macarrão seco - argola lisa $(n=1)$ \\
\hline L & macarrão seco - talharim c/ ovos $(n=1)$ \\
\hline M & massa fresca $p /$ pastel $(n=2)$; nhoque fresco de batata $s /$ recheio $(n=1)$. \\
\hline
\end{tabular}

$\mathrm{n}=$ número de amostras analisadas.

stomacher (Seward 400), em intensidade baixa por 60 segundos. Diluições decimais, a partir da diluição $10^{-1}$, foram preparadas em tubos contendo 9,0 $\mathrm{mL}$ de água peptonada $0,1 \%$ estéril.

\subsection{Contagem de estafilococos coagulase positiva (ECP)}

Alíquotas de 0,1 mL das diluições foram semeadas em ágar Baird-Parker (Acumedia, Lansing, MI, USA) e ágar Vogel e Johnson (Acumedia, Lansing, MI, USA), em duplicata. As placas foram incubadas a $35-37{ }^{\circ} \mathrm{C}$ e, após 48 horas, realizadas a identificação e a contagem das colônias que apresentavam as características típicas e atípicas de Staphylococcus spp. Em meio de cultivo Agar Baird-Parker, essas colônias apresentam-se negras, lustrosas, convexas, rodeadas por halo claro; e em meio de cultivo Agar Vogel-Johnson, apresentam-se negras, pequenas e com halo amarelo (SIQUEIRA, 1995; SILVA et al., 2007; BENNETT e LANCETTE, 2001).

Três colônias características obtidas em cada uma das placas de Baird-Parker e Vogel-Johnson, conforme descrito por Siqueira (1995), foram semeadas em placas contendo ágar Manitol Salgado (7,5\% de $\mathrm{NaCl}$ ) (Oxoid, Basingstoke, Hampshire, England), e incubadas a 35-37 ${ }^{\circ} \mathrm{C}$ por pelo menos 24 horas. Quando o número de colônias características foi inferior a 3 (três), todas as colônias foram semeadas no Manitol Salgado.

Paralelamente, as colônias foram transferidas para um tubo com 3 a $5 \mathrm{~mL}$ de Caldo Infusão Cérebro Coração (BHI) (HiMedia, Mumbai, India), incubado a $35-37{ }^{\circ} \mathrm{C}$ por 18-24 horas para a prova de coagulase. Depois do período de incubação, uma alíquota de $0,5 \mathrm{~mL}$ da suspensão obtida foi transferida para um tubo, ao qual foi adicionado 0,5 $\mathrm{mL}$ de plasma de coelho liofilizado (Laborclin, Pinhais, Paraná) reconstituído de acordo com as instruções do fabricante.

A leitura da prova foi realizada após 4 a 24 horas de incubação a $35-37{ }^{\circ} \mathrm{C}$ (SILVA et al., 2007). As unidades formadoras de colônias de ECP por grama de alimento (UFC/g) foram resultantes do número de colônias fermentadoras de manitol e produtoras de coagulase, considerando-se a diluição correspondente.

\subsection{Determinação do pH}

As amostras foram trituradas e um total de $10 \mathrm{~g}$ foi pesado em um béquer. Depois da adição de $100 \mathrm{~mL}$ de água, o conteúdo foi agitado até que as partículas ficassem uniformemente suspensas, e o $\mathrm{pH}$ foi medido com o aparelho previamente calibrado (Hanna Instruments HI 3221), operado de acordo com as instruções do manual do fabricante (ZENEBON et al., 2008). Os resultados apresentados foram correspondentes às médias das medições realizadas em duas alíquotas derivadas de cada amostra.

\subsection{Determinação da atividade de água $\left(\mathrm{a}_{\mathrm{w}}\right)$}

As amostras foram fragmentadas para permitir que o fundo do recipiente apropriado ao equipamento pudesse ser completamente preenchido. $\mathrm{A} \mathrm{a}_{\mathrm{w}}$ de cada amostra foi determinada individualmente, utilizando medidor de atividade de água (Aqua Lab Dew Point 4TEV). Os resultados apresentados foram correspondentes à média das medições realizadas em duas alíquotas derivadas de cada amostra. 
Avaliação do padrão estafilococos coagulase positiva estabelecido pela legislação brasileira para massas alimentícias RESTA, M. S. A. e OLIVEIRA, T. C. R. M.

\subsection{Análise estatística}

Os valores médios de $\mathrm{pH}$ e $\mathrm{a}_{\mathrm{w}}$ obtidos para cada tipo de produto estudado (Massa seca sem recheio, Massa seca com recheio, Massa fresca sem recheio e Massa fresca com recheio) foram comparados, utilizando análise de variância e o teste de médias (teste de Tukey, $\mathrm{p}<0,05)$. As análises foram realizadas utilizando o software Statistica 7.0 (Statsoft Inc., Tulsa, OK, EUA) e a planilha eletrônica Microsoft@ Excel@ 2010, versão 14.0.6112.5000 (32 bits) (Microsoft Corporation, Pasadena, CA, USA).

\section{Resultados e discussão}

\subsection{Resultados}

Todas as 50 amostras de massas alimentícias analisadas apresentaram contagem de ECP menor do que 10 UFC/g, portanto abaixo do limite máximo estabelecido pela Resolução RDC n 12/2001, da ANVISA, que é de $5,0 \times 10^{3} \mathrm{UFC} / g$ (BRASIL, 2001).

As médias de $a_{w}$ das amostras analisadas neste trabalho são apresentadas na Tabela 2. Os valores de $a_{w}$ encontrados não apresentaram diferença significativa a $p<0,05$ entre as médias calculadas para as massas frescas, independentemente da presença de recheio $(0,96 \pm 0,02)$. As massas secas com e sem recheio apresentaram médias de $\mathrm{a}_{\mathrm{w}}$ significativamente diferentes entre si e entre as massas secas sem recheio $(0,61 \pm 0,07)$ e com recheio $(0,70 \pm 0,03)$.

As médias de $\mathrm{pH}$ das amostras estão apresentadas na Tabela 3. Os valores de $\mathrm{pH}$ encontrados variaram entre 5,69 $\pm 0,43$ e 6,12 $\pm 0,23$. As massas frescas sem recheio apresentaram média significativamente menor $(5,69 \pm 0,43)$ que as massas frescas $(6,03 \pm 0,15)$ e secas $(6,12 \pm 0,23)$ com recheio. Não ocorreu diferença entre a média de $\mathrm{pH}$ das massas secas sem recheio $(5,79 \pm 0,23)$, quando comparada com as médias obtidas com os outros três tipos de massa.

Tabela 2. Médias de $a_{w}$ das amostras analisadas por tipo de massa alimentícia.

\begin{tabular}{ccc}
$\begin{array}{c}\text { Tipo de } \\
\text { massa alimentícia }\end{array}$ & $\begin{array}{c}\text { Número de } \\
\text { amostras } \\
\text { analisadas }(\mathbf{n})\end{array}$ & $\begin{array}{c}\text { Médias de } \\
\mathbf{a}_{\mathbf{w}}\end{array}$ \\
Massa seca SEM recheio & 16 & $0,61^{\mathrm{c}} \pm 0,07$ \\
Massa seca COM recheio & 8 & $0,70^{\mathrm{b}} \pm 0,03$ \\
Massa fresca SEM recheio & 14 & $0,96^{\mathrm{a}} \pm 0,02$ \\
Massa fresca COM recheio & 12 & $0,96^{\mathrm{a}} \pm 0,01$ \\
\hline
\end{tabular}

Médias assinaladas com letras diferentes são significativamente diferentes pelo teste de Tukey $(p<0,05)$.

\subsection{Discussão}

A contagem de ECP nas 50 amostras analisadas neste trabalho foi menor que $10 \mathrm{UFC} / \mathrm{g}$. Swartzentruber et al. (1982) também encontraram baixa contaminação por ECP (<3 NMP), após análise de 1.607 amostras de macarrão seco e 1.477 amostras de "noodles" seco.

A atividade de água $\left(a_{w}\right)$ e o pH são características intrínsecas dos alimentos que interferem no desenvolvimento microbiano (JAY, 2005; DAMODARAN et al., 2010) e, por conseguinte, na produção de seus metabólitos, como as enterotoxinas produzidas por isolados enterotoxigênicos de Staphylococcus spp. Contagens acima de $10^{3}$ UFC de ECP indicam condições higiênico-sanitárias inadequadas de processamento. Normalmente contagens acima de $10^{5}$ UFC de Staphylococcus spp. enterotoxigênicos por grama de alimento são necessárias para haver produção de enterotoxina em quantidade suficiente para causar intoxicação alimentar (GENIGEORGIS, 1989).

$\mathrm{O} \mathrm{pH}$ das massas alimentícias estudadas no presente trabalho variou de 5,69 a 6,12. Embora ECP possa se multiplicar em $\mathrm{pH}$ igual ou superior a 4,2 (ZINK e BOHM, 2005; JAY, 2005), outras características intrínsecas relevantes, como a $a_{w}$, devem ser consideradas. Valores de $a_{w}$ abaixo de 0,86 são limitantes ao desenvolvimento de Staphylococcus spp. (GAVA, 1984; SIQUEIRA, 1995; JAY, 2005; FRANCO e LANDGRAF, 2008). No presente trabalho, as médias de $a_{w}$ obtidas para massas secas com e sem recheio estavam abaixo desse limite $(0,70 \mathrm{e}$ 0,61, respectivamente).

A necessidade de se investigar a ocorrência de ECP nesse produto torna-se questionável, já que nestas condições, a multiplicação de ECP fica comprometida e a produção de toxina estafilocócica pouco provável. Por outro lado, a média de $a_{w}$ para massas frescas com e sem recheio foi de 0,96. A legislação brasileira, portanto, poderia utilizar a umidade ou $\mathrm{a}_{w}$ como parâmetro para determinar em quais tipos de massas o padrão ECP deveria ser pesquisado, ou seja, aplicável apenas para massas alimentícias cruas que apresentassem condições favoráveis à multiplicação de Staphylococcus spp. e à produção de suas enterotoxinas $\left(a_{w}>0,86\right)$.

Tabela 3. Médias de $\mathrm{pH}$ das amostras analisadas por tipo de massa alimentícia.

\begin{tabular}{lcc}
$\begin{array}{c}\text { Tipo de } \\
\text { massa alimentícia }\end{array}$ & $\begin{array}{c}\text { Número de } \\
\text { amostras } \\
\text { analisadas }(\mathbf{n})\end{array}$ & $\begin{array}{c}\text { Médias } \\
\text { de } \mathbf{p H}\end{array}$ \\
\hline Massa seca SEM recheio & 16 & $5,79^{\mathrm{a}, \mathrm{b}} \pm 0,23$ \\
Massa seca COM recheio & 8 & $6,12^{\mathrm{a}} \pm 0,23$ \\
Massa fresca SEM recheio & 14 & $5,69^{\mathrm{b}} \pm 0,43$ \\
Massa fresca COM recheio & 12 & $6,03^{\mathrm{a}} \pm 0,15$ \\
\hline
\end{tabular}

Médias assinaladas com letras diferentes são significativamente diferentes pelo teste de Tukey $(p<0,05)$. 
Embora a média de $a_{w}$ das massas frescas com e sem recheio obtida neste trabalho possibilite a multiplicação de Staphylococcus spp., todas as amostras analisadas apresentaram contagens de ECP menores que $10 \mathrm{UFC} / \mathrm{g}$, o que indicou condições adequadas de processamento e armazenamento das massas alimentícias analisadas.

Autores que avaliaram massas frescas recheadas ou não comercializadas no Brasil encontraram diferentes níveis de contaminação por ECP. Comelli et al. (2011) analisaram um total de 40 amostras de massas alimentícias refrigeradas industrializadas (24 amostras) e caseiras (16 amostras) e encontraram 3 amostras (2 industrializadas e 1 caseira) com contagens acima de $10^{2} \mathrm{UFC} / \mathrm{g}$. Por outro lado, em um estudo realizado com massas frescas produzidas e comercializadas em Londrina, PR, Brasil, todas as amostras analisadas estavam contaminadas com ECP, algumas com contagens superiores a 5,0 × 10 3 UFC/g (FERRARI et al., 2007).

Apesar dos relatos no Brasil de massas alimentícias contaminadas com ECP, é importante salientar que a indústria de massas brasileira nos últimos anos investiu em tecnologia, equipamentos de última geração e capacitação dos profissionais, resultando em um parque industrial entre os mais modernos do mundo (ABIMA, 2012). Os controles estabelecidos na cadeia de produção diminuem o risco de contaminação e a posterior multiplicação de ECP, o que leva, consequentemente, à diminuição do risco da presença de enterotoxinas estafilocócicas neste tipo de produto. Além disso, outros fatores intrínsecos e extrínsecos são considerados para o armazenamento desses produtos, de forma a constituir barreiras à contaminação e multiplicação de ECP. As massas frescas possuem conservantes e aditivos em suas formulações, algumas possuem embalagens com atmosfera modificada e são comercializadas sob refrigeração $\left(4\right.$ a $\left.10^{\circ} \mathrm{C}\right)$

É muito importante ressaltar que a ausência de células viáveis de Staphylococcus spp. no momento da análise do produto final não assegura que o produto esteja livre de enterotoxinas estafilocócicas, devido à sua termoestabilidade (LANCETTE e TATINI, 1992). Somente a detecção de enterotoxinas no produto final poderia contestar a sua inocuidade definitivamente, entretanto a detecção de enterotoxinas diretamente nos alimentos é difícil de ser utilizada na rotina laboratorial devido ao seu alto custo. Torna-se essencial, portanto, o controle de todas as etapas da cadeia produtiva de massas alimentícias por meio da implantação de Boas Práticas de Fabricação (BPF) e do Sistema de Análise de Perigos e Pontos Críticos de Controle (APPCC).

A legislação europeia (CE, 2005) não estabelece critérios para o padrão ECP em massas alimentícias, e não foram encontradas informações sobre este tipo de critério para o referido produto nos websites de órgãos oficiais dos Estados Unidos (FDA, USDA). O padrão para ECP estabelecido na Austrália (AUSTRALIA, 2001), Argentina (ARGENTINA, 2013), Canadá (CANADA, 2008) e Nova Zelândia (NEW ZEALAND, 1995) variou de $10^{3}$ a $10^{4} \mathrm{UFC} / g$. Embora a legislação desses países também estabeleça um único limite máximo, independentemente das diferenças de $a_{w}$ existentes entre os tipos de produtos, não é possível afirmar que nesses países tenha sido realizada uma avaliação de risco que possibilitasse saber se massas alimentícias cruas são associadas com frequência a casos ou surtos de intoxicação estafilocócica. No Brasil, de fato, não há informações disponíveis sobre a implicação de massas alimentícias cruas como responsáveis por veiculação de enterotoxinas estafilocócicas.

Um padrão microbiológico deveria ser estabelecido e aplicado quando há evidências de que o alimento poderia representar um risco à saúde pública ou após uma avaliação de risco. Além disso, esses padrões deveriam ser revisados periodicamente a fim de se manterem atualizados quanto a patógenos emergentes, tecnologias em desenvolvimento e novos conhecimentos científicos como preconiza o Codex Alimentarius (1997).

O avanço tecnológico da indústria de massas alimentícias, que reduziu o contato do manipulador com o produto, da aplicação de embalagens com atmosfera modificada e o uso de conservantes associados à conservação refrigerada, assim como a baixa contaminação por ECP nas massas industrializadas encontrada neste trabalho, permitem conjecturar sobre a necessidade do estabelecimento desse padrão microbiológico, principalmente, para massas secas.

A partir dos resultados do presente trabalho pode-se inferir que é necessária a realização de análises laboratoriais sistemáticas dos produtos alimentícios produzidos no mercado interno para estabelecer padrões microbiológicos coerentes com as condições higiênicosanitárias de processamento desses produtos.

\section{Conclusões}

A média de $a_{w}$ das massas secas com e sem recheio variou de 0,70 a 0,61, respectivamente, o que impossibilita a multiplicação de ECP e a produção de toxina estafilocócica. Como a média de $a_{w}$ das massas frescas foi de 0,96, esse parâmetro intrínseco poderia ser utilizado para determinar em quais tipos de massas o padrão ECP deveria ser pesquisado, ou seja, em massas alimentícias cruas que apresentassem condições favoráveis à multiplicação de $S$. aureus enterotoxigênicos $\left(a_{w}>0,86\right)$. 
Avaliação do padrão estafilococos coagulase positiva estabelecido pela legislação brasileira para massas alimentícias RESTA, M. S. A. e OLIVEIRA, T. C. R. M.

\section{Referências}

ASSOCIAÇÃO BRASILEIRA DAS INDÚSTRIAS DE MASSAS ALIMENTÍCIAS - ABIMA. Exportação - Massas brasileiras. Disponível em: <http://www.abima.com.br/estMassas Brasileiras. asp >. Acesso em 02 jul. 2012.

ARGENTINA. Administración Nacional de Medicamentos, Alimentos e Tecnologia Medica. Codigo Alimentario Argentino. Capítulo IX - Alimentos farináceos - cereales, harinas y derivados. Artículos: 643 al 766. Actualizado al 03/2013. Disponível em: <http://www.an mat.gov.ar/alimentos/codigoa/ CAPITULO_IX.pdf>.Acesso em: 22 mar. 2013.

AUSTRALIA. Food Standards. Microbiological Limits for Foods. Guide to Standard 1.6.1 - Microbiological Limits for Food with Additional Guideline Criteria. Camberra, 2001. Disponível em: <http://www.foodstandards.gov.au/_srcfiles/ Micro_0801.pdf>. Acesso em 22 mar. 2013.

BENNETT, R. W.; LANCETTE, G. A. Staphylococcus aureus. In: FOOD AND DRUG ADMINISTRATION - FDA.

BAM - Bacteriological Analytical Manual Online. 8th ed. rev. Silver Spring: FDA, 2001. cap. 12.

BRASIL. Ministério da Saúde, Agência Nacional de Vigilância Sanitária. Resolução RDC n 93, de 31 de outubro de 2000. Dispõe sobre o regulamento técnico para fixação de identidade e qualidade de massa alimentícia. Diário Oficial da República Federativa do Brasil, Brasília, DF, 01 nov. 2000. Seção 1.

BRASIL. Ministério da Saúde. Agência Nacional de Vigilância Sanitária. Resolução RDC n 12, de 02 de Janeiro de 2001. Aprova o regulamento técnico sobre padrões microbiológicos para alimentos. Diário Oficial da República Federativa do Brasil, Brasília, DF, 10 jan. 2001. Seção 1.

BRASIL. Ministério da Saúde. Agência Nacional de Vigilância Sanitária. Resolução - RDC n²63, de 22 de setembro de 2005. Aprova o Regulamento Técnico para produtos de cereais, amidos, farinhas e farelos. Diário Oficial da República Federativa do Brasil, Brasília, DF, 23 set. 2005.

CANADA. Government of Interpretative Summary. Health Products and Food Branch (HPFB) Standards and Guidelines for Microbiological Safety of Food. Ottawa: Health Products and Food Branch (HPFB), 2008.

COMISSÃO DAS COMUNIDADES EUROPEIAS - CE. Regulamento (CE) n² 2073/2005 da Comissão, de 15 de Novembro de 2005, relativo a critérios microbiológicos aplicáveis aos gêneros alimentícios. Jornal Oficial da União Europeia, L 338/1, 22 dez. 2005.

CODEX ALIMENTARIUS. CAC/GL 21 - 1997 - Principles for the Establishment an Application of Microbiological Criteria for Food. Disponível em: <http://www.codexalimentarius.org/
download/standards/394/CXG_021e.pdf>. Acesso em 20 fev. 2013.

COMELLI, C.; CHIARINI, E.; PRADO, S. P. T.; OLIVEIRA, M. A.; BERGAMINI, A. M. M. Avaliação microbiológica e da rotulagem de massas alimentícias frescas e refrigeradas comercializadas em feiras livres e supermercados. Alimentos e Nutrição, Araraquara, v. 22, n. 2, p. 251-258, 2011

DAMODARAN, S.; PARKIN, K. L.; FENNEMA, O. R. Química de Alimentos de Fennema. 4. ed. Porto Alegre: Artmed, 2010. $900 \mathrm{p}$.

FERRARI, R. G.; WINKLER, S. M.; OLIVEIRA, T. C. R. M. Avaliação microbiológica de alimentos isentos de registro no Ministério da Saúde. Semina: Ciências Agrárias, Londrina, v. 28, n. 2, p. 241-250, 2007.

FRANCO, B. D. G. M.; LANDGRAF, M. Microbiologia dos Alimentos. São Paulo: Atheneu, 2008. 182 p.

GAVA, A. J. Princípios de Tecnologia de Alimentos. São Paulo: Nobel, 1984. 284 p.

GENIGEORGIS, C. A. Present state of knowledge on staphylococcal intoxication. International Journal of Food Microbiology, Philadelfia, v. 9, n. 4, p. 327-360, 1989.

INTERNATIONAL PASTA ORGANISATION - IPO. The world pasta industry in 2011. Roma: IPO, 2011. Disponível em: <http://www. internationalpasta.org/resources/extra/file/IPO \%20A GM\%20 2012/IPOreport2012fin2stat.pdf>. Acesso em 07 dez. 2012.

JAY, J. M. Microbiologia de Alimentos. 6. ed. Porto Alegre: Artmed, 2005. $712 \mathrm{p}$.

KOTIRANTA, A.; LOUNATMAA, K; HAAPASALO, M. Epidemiology and pathogenesis of Bacillus cereus infections. Microbes and Infection, Paris, v. 2, n. 2, p. 189-198, 2000. http://dx.doi. org/10.1016/S1286-4579(00)00269-0

LANCETTE, G. A.; TATINI, S. R. Staphylococcus aureus. In: VANDERZANT, C.; SPLITTSTOESSER, D. F. (Ed.). Compendium of Methods for the Microbiological Examination of Foods. 3rd ed. Washington: American Public Health Association, 1992. cap. 33, p. 533-592.

NEW ZEALAND. Ministry of Health. The Food Administration Section. Microbiological reference criteria for food. In: FOOD Administration Manual. version 2.0. Wellington, 1995. 25 p. Disponível em: <http://www.foodsafety.govt.nz/elibrary/industry/ microbiological_reference-guide_assess.pdf>. Acesso em: 22 mar. 2013.

SILVA, N.; JUNQUEIRA, V. C. A.; SILVEIRA, N. F. A.; TANIWAKI, M. H.; SANTOS, R. F. S.; GOMES, R. A. R. Manual de Métodos de Análise Microbiológica de Alimentos. 3. ed. São Paulo: Varela, 2007. 536 p. 
Avaliação do padrão estafilococos coagulase positiva estabelecido pela legislação brasileira para massas alimentícias RESTA, M. S. A. e OLIVEIRA, T. C. R. M.

SIQUEIRA, R. S. Manual de Microbiologia de Alimentos. Brasília: Embrapa/SPI; Rio de Janeiro: Embrapa/CTAA, 1995. $159 \mathrm{p}$.

SWARTZENTRUBER, A; PAYNE, W. L.; WENTZ, B. A.; BARNARD, R. J.; READ JUNIOR, R. B. Microbiological quality of macaroni and noodle products obtained at retail markets. Applied and Environmental Microbiology, Washington, v. 44, n. 3 , p. 540-543, 1982.

TONDO, E. C.; BARTZ, S. Microbiologia e Sistemas de Gestão da Segurança de Alimentos. Porto Alegre: Sulina, 2012. 263 p.
ZENEBON, O.; PASCUET, N. S.; TIGLEA, P. Métodos Físicoquímicos para Análise de Alimentos. 4. ed. São Paulo: Instituto Adolfo Lutz, 2008. 1020 p. Primeira edição digital.

ZINK, D.; BOHM, S. B. Potentially Hazardous Food: The Evolving Definition of Temperature Control for Safety. Rhode Island: NEHA Annual Education Conference, June 262005. 31 p. Disponível em: <http://www.fda.gov/downloads/food/ guidanceregu lation/ucm111211.ppt>. Acesso em: 01 fev. 2013. 